\section{COMPLEX: An Applesoft BASIC program to assess preference for visual complexity}

\author{
RICHARD DENI and RICHARD J. COFFEE \\ Rider College, Lawrenceville, New Jersey
}

Since Berlyne's classic work on prefe rence for environmental complexity (e.g., Berlyne \& Boudewijns, 1971), visual preference tests have been used widely in experiments dealing with a range of basic and applied research objectives. Research applications in the area of basic personality structure (Wiedl, 1977) are representative of the use of this technique in the study of adjustment and clinical psychology. Preference for complexity has also been incorporated into work on cognitive style and information processing (Frost \& Lindauer, 1980), cognitive development in young children (Burton, 1981), and social-filial attitudes (Lohmann \& Wiedl, 1977). The basic technique has proved to generalize well across disciplines, settings, and topic areas.

The program described here can be used to obtain a range of behavioral measures related to visual preference. It can also be used to carry out experimental procedures involving a number of possible independent variables. The program also has potential use as an instructional tool for courses in information processing, cognitive psychology, personality, individual differences, and assessment.

\section{Program Operation}

Hardware requirement. The COMPLEX program requires an Apple IIe computer with one disk drive, a color or a monochrome display, and a real-time clock (Apple Clock, by Mountain Computer, Inc.). Color display capability allows for the manipulation of an additional variable.

Picture stimulus simulation. Line drawings are displayed on the video screen using high-resolution graphics statements (Kamins, 1982, p. 142). A graphics display grid is set for 280 columns $\times 160$ rows. Individual straight lines may be drawn within this grid using the HPLOT statement (Kamins, 1982, p. 146). Four values, two pairs of $\mathrm{x}-\mathrm{y}$ coordinates, are read by the program to draw each individual line. Selection of coordinate pairs determines where the line will appear on the display, its angle, and its length. To draw connected lines, the last coordinate pair of the previous line must match the first coordinate pair of the next line. To close the figure, the final coordinate pair must match the first pair of the first line drawn. Picture stimuli may be limited to a single straight line of a given length or may be extended

The authors' mailing address is: Department of Psychology, Rider College, Lawrenceville, NJ 08648. to displays of multiple lines, either connected end to end or disconnected (scattered). The user may draw recognizable figures or randomly generated figures, depending upon the selection of coordinate pairs for plotting.

Variables controlled by the program. The experimenter sets the number of trials per session and several factors comprising levels of possible independent variables. Variables pertaining to the picture stimulus display include: (1) the number of lines in the display, (2) whether the line pattern is determined at random or by preset values, (3) if random, whether the figure will be open or closed, (4) the color of the lines drawn, (5) which part of the grid is used for the picture stimulus and (6) how long the picture will be displayed. All timing is carried out using time-string manipulation. Each reading of the real-time clock returns a single time string showing the date, hours, minutes, seconds, and fraction. VAL and MID\$ functions are used to convert this string into digital running time (Mountain Computer, Inc., 1982, p. 13). To test different groups of subjects under different conditions as part of the same study, the experimenter should set up a separate working version of the program for each group or variable combination.

Measurement of dependent variables. For each trial in the session, the picture stimulus is presented first, followed by a message in the text "window" at the bottom of the screen. This message is user defined and requests that the subject enter a "rating" judgment for that picture. The rating scale is defined by the user. For example, if the user wants to assess "pleasantness," the text prompt can be written to ask for a pleasantness rating. If the user wants to assess whether the figure is "interesting" or not, the text prompt can be written to ask for an interest rating. Ratings are on a numeric scale. The standard scale is $1-9$, but the scale may be modified. The numeric entry is stored in an array for later printing. In addition to the rating itself, the program stores the processing time used by the subject in making the individual rating. This response-latency timer is begun at the end of the display of the picture stimulus and is read as the subject enters the rating response. These two measures are stored for each trial. At the end of the test session, a sequential-access file is opened on disk, and the raw data lists (organized by trial) are written into this file. Raw data are not immediately printed so that multiple sessions and/or program chaining may be used. "Output" files are to be printed using the utility program COMPLEX-PRINT provided with the control program. COMPLEX-PRINT displays raw data by trial in column format for the display or printer.

\section{Availability}

A program listing may be obtained at no charge from 
Richard Deni, Department of Psychology, Rider College, Lawrenceville, New Jersey 08648.

\section{REFERENCES}

Berlyne, D., \& Boudewijns, W. (1971). Hedonic effects of uniformity in variety. Canadian Journal of Psychology, 25, 195-206.

Burton, L. E. (1981). The relationship between selected measures of preference for visual stimulus complexity and cognitive abilities in young children (Doctoral dissertation, Oklahoma State University, 1981). Dissertation Abstracts International, 42, $2028 A$.

Frost, A. G., \& Lindauer, M. S. (1980). Preferences for figural complexity as a function of cognitive style. Bulletin of the Psychonomic Society, 16, 221-224.

Kamins, S. (1982). Applesoft BASIC programmer's reference manual (Vol. 1). Cupertino, CA: Apple Computer, Inc.

Lohmann, J., \& WiedL, K. H. (1977). Perceptions of parental upbringing and preference for visual complexities. Zeitschrift für Entwicklungspsychologie und Padagogische Psychologie, 9, 103-112.

Mountain Computer, Inc. (1982). The clock operating manual. Scotts Valley, CA: Author.

WIEDL, K. H. (1977). Structure and personality correlates of aesthetic preferences for visual complexity. Zeitschrift für Psychologie, 185, 237-256.

(Revision accepted for publication March 30, 1984.) 